TERRA. Revista de Desarrollo Local

e-ISSN: 2386-9968

Número 6 (2020), 358-364

DOI 10.7203/terra.6.16907

IIDL - Instituto Interuniversitario de Desarrollo Local

\title{
Reseña. La sociedad valenciana en transformación (1975-2025)
}

\section{José Navarro Pedreño}

Dpto. de Agroquímica y Medio Ambiente (Universidad Miguel Hernández de Elche, España)

jonavar@umh.es

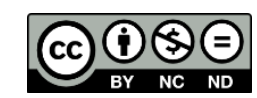

Esta obra se distribuye con la licencia Creative Commons Reconocimiento-NoComercial-SinObraDerivada 4.0 Internacional 


\section{SECCIÓN RESEÑAS}

\section{Reseña. La sociedad valenciana en transformación (1975-2025)}

Resumen. Esta compleja obra abarca un espacio de tiempo inacabado ya que nos lleva al año 2025, que le da el valor de la prospectiva. Es un estudio detallado y un análisis crítico de la sociedad valenciana que nos lleva a determinar lo que somos en la actualidad, como hemos evolucionado en estos últimos años y cuáles son los conflictos a los que tendremos que hacer frente. Se convierte en un libro imprescindible para entender la estructura social, sus valores, la relación de estos con la economía, la política y la acción social. No está exenta de críticas al sistema social, económico y político, y de pautas que deben hacernos reflexionar a los agentes sociales y a la ciudadanía. Los autores dejan ver a las claras su preocupación por la senda que recorremos como sociedad los valencianos.

Palabras clave: desigualdades territoriales, estructura social, género, población, pobreza, política regional, sociedad digital, turismo, valores sociales.

Recibido: 16 de marzo de 2020

Devuelto para revisión: -

Aceptado: 16 de marzo de 2020

\section{Referencia / Citation:}

Navarro, J. (2020). Reseña. La sociedad valenciana en transformación (1975-2025). TERRA. Revista de Desarrollo Local, (6), 358-364. DOI 10.7203/terra.6.16907 


\section{Antonio Ariño (Dtor.) y Pedro García Pilán (Coord.) \\ LA SOCIEDAD VALENCIANA EN TRANSFORMACIÓN (1975-2025)}

Publicacions de la Universitat de València (PUV), 2018. 593 páginas.

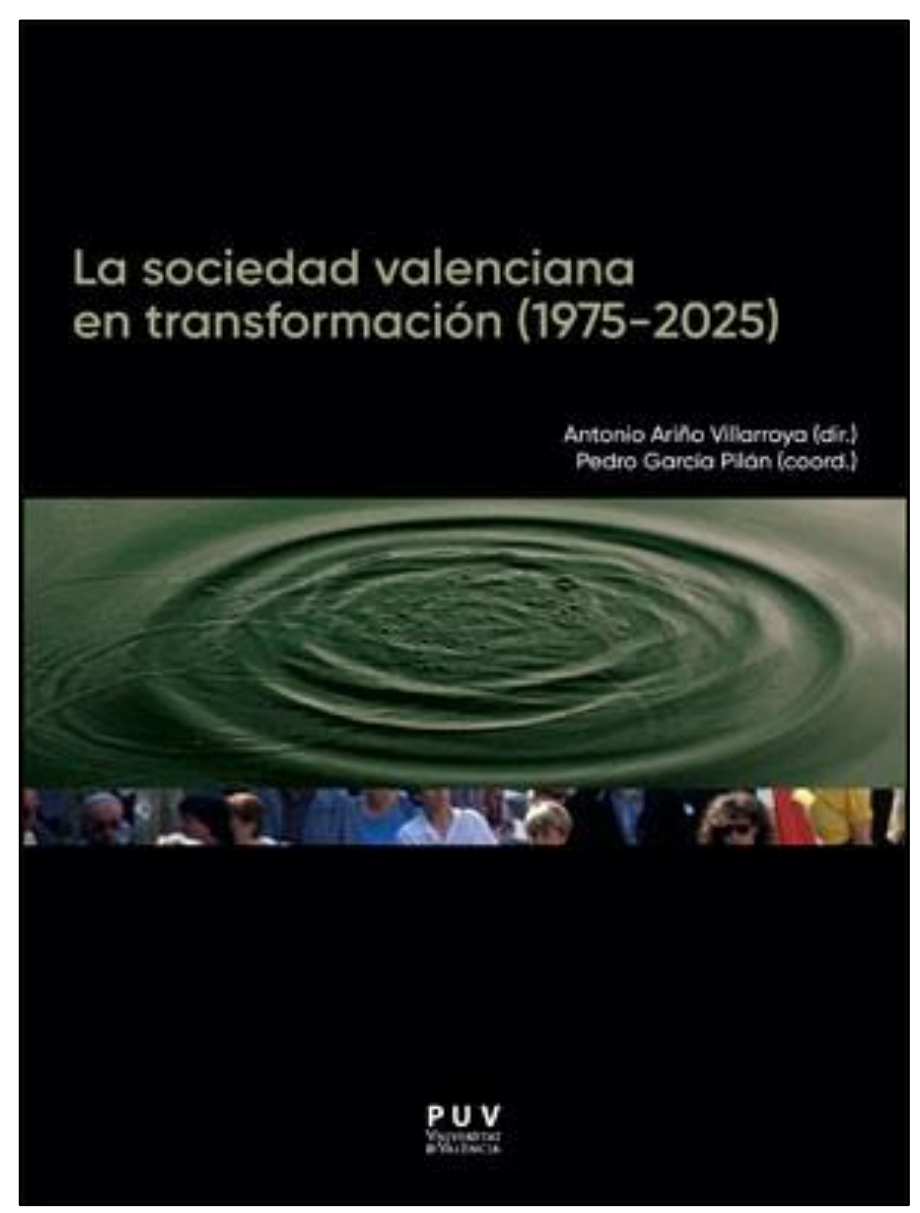

Resulta complejo realizar una reseña de una obra que aborda de forma ambiciosa el análisis de la sociedad valenciana en estos últimos años $y$ en la que participan cincuenta autores, todos ellos de reconocido prestigio. La base de esta obra es indudablemente sociológica, pero atiende a muy diversos aspectos que incluyen la economía y un acercamiento al medio ambiente. Sin duda es un texto que refleja a la perfección un decalustro de la Comunidad Valenciana, de la sociedad valenciana marcada por la llegada de la democracia y la autonomía de la región hasta el momento presente, de madurez y de vértigo ante los retos que se deben afrontar.

Realmente, este análisis se plantea con fines prospectivos, es decir, propositivos y de planteamiento de futuro. Por ello abarca un periodo de cincuenta años que todavía no cumplimos pero que el año 2025 está ahí, lo que le da el valor añadido de servir de referencia para prepararnos de cara al futuro inmediato.

Es una obra coral, en la que ya se ha indicado que las Ciencias Sociales tienen la principal voz, desde la visión sociológica, antropológica, económica y geográfica. La obra, aparentemente sigue el esquema clásico en este tipo de estudios, comenzar por el análisis de la población, el territorio, las actividades económicas y las relaciones sociales. Sin embargo, da un paso más, gracias a la incorporación de la perspectiva ambiental en alguno de sus apartados. Pero que es el medio ambiente sino el ser humano y su entorno, interaccionando.

Destaca que profundiza en la línea trazada hace años en el ámbito de la Sociología, en la que esta ciencia deja de ser una herramienta descriptiva, para convertirse en un potente instrumento de análisis, la Sociología analítica, remarcado al introducirnos en la lectura del texto.

El resultado del libro es revelador de cómo hemos evolucionado los valencianos y de los retos, o designios, a afrontar. Conviene indicar que no es una obra exenta de críticas sobre la situación actual y formula propuestas para un cambio de rumbo, especialmente en temas como la gobernabilidad, los valores sociales o el estado de bienestar. Como reseña 
más destacable quiero resaltar que este libro muestra la alta sensibilidad de la dinámica social valenciana al cambio, a los efectos de las crisis y en alguna medida, trata de no caer en el centralismo valenciano que ha marcado en ocasiones estos años de autonomía que, por ende, parece inevitable por el empuje de València y su entorno inmediato. En estos momentos de crisis sanitaria por la presencia de una pandemia asociada al virus “Coronavirus disease 2019 (COVID-19)", de nuevo tendrá que salir a la luz esa capacidad y dinamismo para hacer frente a las crisis de forma flexible.

\title{
Figura 1. Índice de contenidos
}

\author{
Población: dinámica y estructura

Gloria María Caravantes López de Lerma

Oscar Barberà Aresté, Antonio Ariño Villarroya, Pedro García Pilán, Marc Borrás Barberà, Anna I. López Ortega, Pere

J. Beneyto, Antonio Alaminos, Astrid Barrio López

Fuente: https://dialnet.unirioja.es/servlet/libro?codigo=726566 (consulta realizada el 25/03/2020). 
Desde la óptica positivista, es importante manifestar la alta adaptabilidad que le conceden los autores a la sociedad valenciana y por tanto la capacidad de sobreponerse a circunstancias adversas, al mismo tiempo que se razona la debilidad que tenemos al estar expuestos a cambios que nos afectan de forma rápida, casi más que en ningún otro territorio europeo. El turismo es un ejemplo, como actividad básica en la Comunitat Valenciana es fiel reflejo de la sensibilidad y la posible debilidad de situaciones adversas propias y ajenas.

Sin querer plantear un análisis exhaustivo de la obra, conviene indicar que cada uno de los capítulos es por sí mismo, una fuente de información, inspiración y análisis, y que constituyen por sí mismo un "corpus" sobre la temática o temáticas que tratan. No me resisto a señalar algunas de las coordenadas que los lectores no deben dejar pasar en cada uno de los capítulos, siendo injusto en esta selección porque son muchas las claves que se aportan. Del mismo modo, voy a obviar la lista de autores que aportan, desde las Ciencias Sociales, su contribución a esta obra, pertenecientes fundamentalmente a la Universitat de València y a la Universidad de Alicante, con colaboradores de la Universitat Politècnica de València, Universitat Jaume I, Museo Valenciano de la Ilustración y la Modernidad, Observatorio para el Desarrollo de la Economía Digital en España y Tribunal Superior de Justicia de València.

Centrándonos en el capítulo que abre la obra, "la población, su dinámica y estructura, en él, sus autores Castelló-Cogollos y Moncusí-Ferré nos recuerdan que, a pesar de los vaivenes demográficos, la inercia que determina la estructura de la población por edad y sexo marcará el futuro de la sociedad y alertan de los procesos de pérdida de población por la crisis, la emigración y del problema del envejecimiento.

Tras unas apasionantes cincuenta y dos páginas sobre la población, se abre paso "el modelo territorial". En este apartado coordinado por Julia Salom, no debemos dejar pasar los datos aportados sobre la crisis de 2008, el freno a la actividad de construcción y el sellado del suelo con pérdida de suelos fértiles de huertas, que fue tan espectacular en los años anteriores a dicha crisis. La gran pérdida de servicios ecosistémicos en plena fiebre del ladrillo, generando modelos de baja densidad y urbanización dispersa en las periferias urbanas es una de las consecuencias llamativas de este proceso expansivo de la construcción. Pero el marco institucional y la gobernabilidad valenciana no son ajenos en este capítulo al modelo territorial, sino que van unidos y tienen su responsabilidad en el modelo territorial. Destacan los autores los pocos avances significativos en favor de una mayor coherencia y desarrollo territorial sostenible.

La adaptación y el cambio, comparable a etapas históricas previas del Reino de Valencia, desde el prisma de la economía y el cambio climático, es el objeto del tercer capítulo coordinado por Juan Romero. Destacar la existencia de diferentes modelos económicos y motores de cambio, asociados a la diversidad valenciana de norte a sur, tanto económica como social. Los desafíos que plantea el clima y la sostenibilidad, incluido el sector que ocupa a un porcentaje importante de la población, el turismo, se reflejan en los distintos apartados. Nos encamina este capítulo, finalmente, hacia la sociedad digital, que inevitablemente llega y que será el reto inmediato a afrontar en el que debemos tener éxito.

Sin alejarnos del ámbito económico, los autores García Calavia y Sanchis Gómez nos introducen en "la estructura laboral valenciana". La desigualdad, las diferencias entre sector público y privado, las empresas existentes y el encaje dentro del marco nacional y europeo de la Comunitat, así como la distribución de renta, están tratados de forma 
concisa. Se refleja de este análisis una sociedad diversa y con muchas particularidades, y persistentes desigualdades.

Estos apartados anteriores nos dejan a Valencia como centro de las inversiones públicas y tractor de las privadas, pero a pesar de este hecho, se indica que la Comunidad Valenciana está bastante equilibrada, especialmente en el caso de la provincia de Alicante. Pero la renta, la distribución de riqueza y el crecimiento, y ese espejismo económico del retraso en la renta por habitante de los valencianos con respecto al resto de España, son tratados con gran definición en el capítulo dedicado a "crecimiento y distribución: desigualdad, pobreza y condiciones de vida". Es quizás, uno de los apartados más importantes en el que Francisco José Goerlich deja a la vista de todos la pobreza y la desigualdad existentes dentro de nuestro territorio. Una guía de necesidades para que se preste atención desde las administraciones.

Las rentas, y las posibilidades derivadas de ellas condicionan a "las familias, convivencias y trayectorias vitales", tratadas en el capítulo sexto que coordina Mercedes Alcañiz. La sociedad valenciana es reflejo de cambios notables en las formas de familias, en los tipos de matrimonio y en las opciones de paternidad/maternidad. Pero la igualdad en los roles de género todavía no se alcanza y se mantienen desigualdades entre mujeres y hombres. Así que resulta necesario unir a este capítulo el séptimo, "transformaciones en la definición y práctica social de las mujeres". Los datos aportados bajo la batuta de Capitolina Díaz, confirman que se está todavía lejos de alcanzar un reparto justo en el ámbito del poder, lejos de romper la desigualdad laboral y salarial asociada al género.

El octavo capítulo nos conduce al análisis del "bienestar y las políticas sociales" en el que el equipo coordinado por Francesc Xavier Uceda-Maza continúa ahondando en cómo es la sociedad, lo que facilita unir los temas anteriormente tratados Es precisamente un ejemplo más de la buena estructuración del libro como conjunto. Bienestar, algo básico si se articulan las políticas y la legislación adecuada, que soporta un sistema sanitario, educativo y de todo tipo de servicios sociales, incluyendo la justicia de la que se habla más adelante, cuyo estancamiento parece haberse alcanzado en los últimos años. La lacra de la violencia de género, permanece latente en nuestra sociedad, como nos recuerdan los autores, remarcando la existencia de partes de nuestro territorio en las que las personas están expuestas a la exclusión y la desigualdad en barrios vulnerables de muchas localidades y especialmente en el sur de la Comunidad, destacando la ciudad de Elche.

Para mejorar socialmente, es básica la educación. Precisamente el noveno de los capítulos trata sobre "el derecho a la educación en la Comunitat Valenciana", donde Francesc Hernàndez y el conjunto de autores que participan, realizan un análisis de los distintos niveles educativos. Destacar dos pinceladas que son significativas sobre la evolución de la educación, el abandono educativo en la Comunidad Valenciana es prácticamente el doble que la media de la Unión Europea, y la expansión del sistema de universidades y los títulos ofertados.

Actividades sociales básicas y motores de la economía son el "consumo, cultura y ocio", tratados por Ramón Llopis y colaboradores con gran detalle en el capítulo décimo. El gasto de los valencianos se contrae, la cultura y su oferta se diversifican, pero la frecuencia de acceso y consumo de la misma no se incrementa. Sin embargo, sí lo hace la práctica deportiva. Son estas algunas de las conclusiones que podemos encontrar en los datos elaborados en este apartado.

El capítulo sobre "los valores en la Comunitat Valenciana", está realizado por Antonio Ariño y muestra un análisis muy detallado sobre lo que construye nuestra sociedad. De los datos podemos considerarnos una sociedad avanzada. En este sentido sí lo demuestran 
los datos, aun cuando persisten reticencias en sectores sociales que afectan tanto a valores de igualdad, género como a comportamientos económicos. Pero quería destacar otra clave que es relevante, el incremento del sentido de pertenencia territorial, con un aumento de la identificación a la localidad, la Comunitat, España y Europa, destacando a la humanidad en su conjunto. Sin entrar en más detalles que se deben consultar en la obra, es importante destacar la identificación con la Comunitat Valenciana, lo que implica un apoyo implícito a la estructura administrativa autonómica a la que se le da valor, siendo mayoritario el sentimiento de ser tan español como valenciano en el conjunto de la sociedad. Con todos los matices que se dan en este capítulo, que son muchos, me permito apuntar que la sociedad valenciana es una sociedad madura o que está apostando firmemente por esa madurez, en valores y estabilidad social. Pero repito, hay matices a los que atender como recordaré más adelante en esta reseña.

Reflejo y sostén de la sociedad son las "acciones colectivas y el sistema político, capítulo coordinado por Oscar Barberà, que nos da las claves de los sistemas de partidos, su evolución, así como sobre las organizaciones de todo tipo que ejercen acciones dentro de la sociedad y para la sociedad, incluidas las empresariales y sindicales. Destacan los autores la decreciente religiosidad, la identificación regional y la moderación ideológica, entre otros aspectos.

El estado de derecho, como señala Pedro Viguer, tiene a la justicia como elemento clave, y no podía ser menos en el caso de la "justicia en la Comunitat Valenciana". Sin ser exhaustivo, es importante valorar como negativo la carga de trabajo de los juzgados y tribunales, la entrada de miles de casos todos los años y la preocupante carga de los tribunales penales de Castellón o Alicante, lo que sin duda dificulta que la justicia sea esa parte significativa que apuntale una sociedad y el estado de derecho que la cobija.

Estas breves pinceladas de los capítulos que componen esta obra, se cierra con una acertada reflexión y crítica, centrada en el autogobierno y el estado de bienestar. Con la más que conveniente necesidad de leerla, para poder entender toda la dimensión del libro. Quisiera, no obstante, quedarme con la afirmación que Antonio Ariño recoge tan acertadamente: "Los tres contratos subyacentes e implícitos en el modelo de Estado de bienestar están en crisis: el contrato social entre clases, el contrato intergeneracional entre grupos de edad y el contrato de género en función del sexo". Y esto es así, porque nada está garantizado. A lo largo del texto hemos visto pasos adelante, también algunos retrocesos sociales, pero en manos de la acción política, la política democrática y la implicación ciudadana.

El valor de una obra también se refleja en las consultas realizadas para su elaboración. En este caso, las casi 600 referencias bibliográficas y 26 fuentes documentales, avalan esta necesaria lectura y le dan más consistencia, si cabe, a la dada por el variado y respetable conjunto de autores, tantos autores como los años seleccionados en este análisis social de la Comunitat Valenciana..

José Navarro Pedreño

Dpto. de Agroquímica y Medio Ambiente Universidad Miguel Hernández de Elche
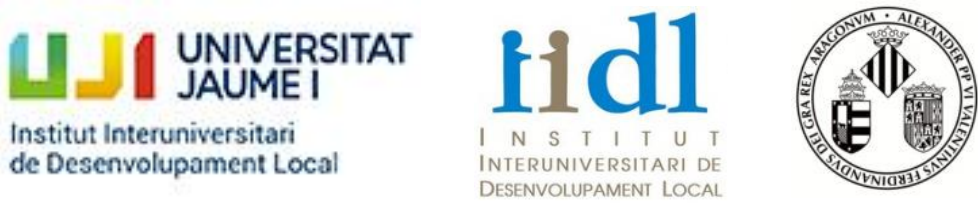